\title{
Surgical Management of Colonic Inertia
}

\author{
Jacob A. McCoy, M.D. ${ }^{1}$ David E. Beck, M.D. ${ }^{2,3}$ \\ 1 University of Texas Medical School, Houston, Texas. \\ ${ }^{2}$ Department of Colon and Rectal Surgery, Ochsner Clinic Foundation, \\ New Orleans, Louisiana. \\ 3 Ochsner Clinical School, The University of Queensland School of \\ Medicine, Brisbane, Australia.
}

\begin{abstract}
Address for correspondence and reprint requests David E. Beck, M.D. Department of Colon and Rectal Surgery, Ochsner Clinic Foundation, 1514 Jefferson Hwy., New Orleans, LA 70121

(e-mail: dbeckmd@aol.com).
\end{abstract}

Clin Colon Rectal Surg 2012; 25:20-23.

\begin{abstract}
Keywords

- constipation

- colectomy

- colonic inertia

- abdominal pain

For the select small number of constipated patients that cannot be managed medically, surgical options should be considered. Increases in our knowledge of colorectal physiology and experience have fostered improvements in patient evaluation and surgical management. Currently, patients with refractory colonic inertia are offered total abdominal colectomy and ileorectal anastomosis, often with laparoscopic techniques. With proper patient selection, the results have been excellent for resolving the frequency and quality of bowel movements. However, symptoms such as bloating and abdominal pain, which may be related to irritable bowel syndrome rather than the colonic inertia, may persist.
\end{abstract}

Objectives: On completion of this article, the reader should be familiar with surgical options to manage colonic inertia.

As discussed in other articles in this issue of Clinics, constipation is a major health problem. For the select small number of patients that cannot be managed medically, surgical options should be considered. Increases in our knowledge of colorectal physiology and experience have fostered improvements in patient evaluation and surgical management. Constipated patients can be divided into those with colonic inertia, outlet obstruction, or both. The management of outlet obstruction is discussed by Dr. Ellis in another article in this issue of Clinics. Here we will address the surgical management of colonic inertia.

\section{Indications and Patient Evaluation}

Colonic inertia is defined as the inability of the colon to modify stool to an acceptable consistency and move the stool from the cecum to the rectosigmoid area at least once every 3 days. ${ }^{1}$ An orderly evaluation can confirm the diagnosis and aids in the selection of patients who will benefit from surgical therapy. ${ }^{1-3}$ The majority of patients referred for surgery are female with a mean age of 40 . The recommended and optional preoperative evaluations are summarized in - Table 1. The evaluations in the recommended column will suffice for most patients. If the history, examination, or initial evaluations suggest other potential problems, the additional studies in the optional column may be required. For example, if the history documents constipation since birth, anal manometry may be requested to determine the absence of an anorectal inhibitory reflex, suggestive of Hirschsprung disease.

In the initial evaluation of constipation, we prefer a barium enema rather than a colonoscopy. In addition to identifying any anatomic cause for constipation (obstructing neoplasm, volvulus, etc.), the films provide information on the diameter, length, and redundancy of the colon. Constipated patients are frequently difficult to cleanse prior to either examination; it is safer to perform a barium enema with a suboptimum preparation than a colonoscopy. It is also difficult to perform a colonoscopy on patients with redundant tortuous colons and associated abdominal pain.

The transit study objectively confirms a slow colonic transit time. ${ }^{3}$ If a film is taken a few hours after ingestion (e.g., have the patient take the capsules late Sunday evening and schedule the first abdominal x-ray early Monday morning), gastric and small bowel dysmotility can be excluded. This first film should show all markers in the colon. Additional abdominal films are obtained at day 3 (Wednesday) and day 5 (Friday). If more than five markers remain in the colon on day
Issue Theme Functional Bowel Disease; Guest Editor, David E. Beck, M.D.
Copyright (C) 2012 by Thieme Medical Publishers, Inc., 333 Seventh Avenue, New York, NY 10001, USA. Tel: +1(212) 584-4662.
Dol http://dx.doi.org/ $10.1055 / \mathrm{s}-0032-1301755$. ISSN 1531-0043. 
Table 1 Patient Evaluation

\begin{tabular}{|l|l|}
\hline Recommended & Optional \\
\hline History & Anal manometry \\
\hline Physical & Cinedefecography \\
\hline Laboratory (hemoglobin, electrolytes, TSH, T4, etc., if not previously obtained) & $\begin{array}{l}\text { Small bowel transit study } \\
\text { (breath hydrogen) }\end{array}$ \\
\hline Anatomic study (barium enema or colonoscopy) & Gastric emptying \\
\hline Transit study & Small bowel follow-through \\
\hline Balloon expulsion test & \\
\hline
\end{tabular}

5, slow colonic transit is documented. Patients are asked to avoid laxatives during the transit study and to report any bowel movements to the examiner. Disappearance of the markers, in the absence of a reported bowel movement, suggests a creditability issue with the patient. Retention of the markers, just proximal to the rectum, may suggest an outlet obstruction. It is important for the surgeon to view the actual x-rays, as many less-experienced radiologists will not give adequate reports (e.g., "markers in the colon").

The balloon expulsion test serves to confirm adequate rectal function and a normal test argues against outlet obstruction. ${ }^{4}$ The first author uses a simplified test, which is easily performed during the initial or subsequent preoperative office visit. ${ }^{4}$

Finally, as in any major operation, the risks and potential benefits must be evaluated for each individual patient. Both the surgeon and the patient must be satisfied of the diagnosis of colonic inertia and understand the proposed procedure, its risks, and outcome.

\section{Surgical Options}

Several procedures have been attempted to treat colonic inertia. These include segmental colectomy, subtotal colectomy with ileosigmoid or cecorectal anastomosis, and total abdominal colectomy with ileorectal anastomosis (TAC IRA). Segmental colectomy is appealing, but it is difficult to determine if only part of the colon does not function properly rather than the entire colon. Transit studies have not been adequately specific or reproducible to document segmental dysmotility. Segmental and subtotal colectomy with ileosigmoid anastomosis frequently result in persistent or recurrent constipation, and up to $50 \%$ of patients who have undergone these procedures have required additional resectional surgery. ${ }^{5,6}$ A cecorectal anastomosis is not an operation performed frequently and has led to higher complication rates including cecal distention. ${ }^{5,7}$ Several studies (- Table 2) ) $^{5,6,8-}$ $15,20-31$ have demonstrated that TAC IRA is the procedure of choice for colonic inertia. The anastomosis is usually performed at the upper rectum (at or slightly above the sacral promontory). An anastomosis at this level is easier to perform and eliminates the risks associated with rectal mobilization.
The upper rectum has a good supply and its size does not limit the size of the anastomotic lumen.

Patients with colonic inertia are often well suited for laparoscopic techniques and studies using these techniques have shown good results by experienced surgeons. ${ }^{28,29}$ Most patients offered surgical therapy are relatively young and active. Neither proximal vessel ligation nor pelvic dissection is required, and cosmetic issues are often important in this patient group. The smaller incisions offer the potential for a lower incidence of wound complications, incisional hernias, and adhesions. Both conventional laparoscopic and hand-assisted techniques have been described. ${ }^{25,28,29}$ The greater flexibility, lower costs, and shorter operative times have led many surgeons, including the first author to prefer a hand-assisted laparoscopic technique.

In an extremely select group of patients with colonic inertia and rectal dysmotility, a restorative proctocolectomy may be considered. Another option is a proctocolectomy and continent ileostomy. Finally, poorer risk patients may be best served with an ileostomy, with or without a colectomy. ${ }^{1}$

\section{Results}

\section{Bowel Function}

The frequency of bowel movements following total colectomy varies from 0.5 to six bowel movements per day. Most patients average one to three movements per day. The frequency reduces with time due to intestinal adaptation. ${ }^{5}$ A summary of the recent published results with total abdominal colectomy and ileorectal anastomosis is presented in - Table 2. Several aspects of these reports merit additional discussion. The relatively small patient numbers reflect the select preoperative criteria most surgeons use for this therapeutic option. The vast majority of patients were young to middle-aged women. Although the follow-up was variable, TAC IRA had an overall success rate exceeding 90\%. Varying criteria were used to measure "success." These included patient's opinions, bowel frequency, symptom relief, and measures of quality of life. A uniform measure has not been adopted. 
Table 2 Total Abdominal Colectomy and Ileorectal Anastomosis

\begin{tabular}{|l|l|c|c|c|c|}
\hline Author & No & Female (\%) & Mean Age (yr) & FU (yr) & Success (\%) \\
\hline Beck et al, $1989^{8}$ & 14 & 100 & 41 & 1.2 & 100 \\
\hline Zenilman et al, $1989^{9}$ & 12 & 100 & 35 & 2 & 100 \\
\hline Pemberton et al, $1991^{6}$ & 38 & 84 & 40 & & 100 \\
\hline Wexner et al, $1991^{10}$ & 16 & 92 & 45 & 1.2 & 94 \\
\hline Mahendrarajah et al, $1994^{11}$ & 9 & 100 & 38 & 1.3 & 88 \\
\hline Piccirillo et al, $1995^{12}$ & 54 & 78 & 49 & 2.2 & 94 \\
\hline Redmond et al, $1995^{13}$ & 34 & 92 & 43 & 7.5 & 90 \\
\hline Pikarsky et al, $2001^{5}$ & 30 & 70 & 60 & 8.9 & 100 \\
\hline FitzHarris et al, $2003^{14}$ & 75 & 97 & & 3.9 & 95 \\
\hline Beck et al, $2005^{15}$ & 40 & 95 & 42 & 3 & 95 \\
\hline Glia et al, $2004^{20}$ & 17 & 94 & 46 & 5 & 71 \\
\hline Thaler et al, $2005^{21}$ & 17 & 100 & 47.8 & 4.9 & 100 \\
\hline Hassan et al, $2006^{22}$ & 59 & 97 & 41 & 6.1 & 100 \\
\hline Choe et al, $2006^{23}$ & 21 & & & 4.8 & 90 \\
\hline Zutshi et al, $2007^{24}$ & 35 & & 38.6 & 10.8 & 77 \\
\hline Hsiao et al, $2008^{25}$ & 44 & 100 & 29 & & 89 \\
\hline jiang et al, $2008^{26}$ & 20 & 95 & 43 & 4 & 65 \\
\hline O'Brien et al, $2009^{27}$ & 13 & 100 & 39 & 8.1 & 100 \\
\hline Pinedo et al, $2009^{28}$ & 100 & 41.5 & 2.1 & 100 \\
\hline Riss et al, $2009^{29}$ & 20 & 100 & 46 & 7 & 50 \\
\hline di Fabio et al, $2010^{30}$ & 12 & 93 & 41 & 3.4 & 93 \\
\hline Sohn et al, $2011^{31}$ & 15 & 37 & 84 & & \\
\hline
\end{tabular}

\section{Quality of Life}

Several authors have documented the patients' quality of life after surgical management. ${ }^{14,16,17}$ FitzHarris and colleagues surveyed 75 patients who had undergone TAC IRA a mean of 3.9 years (range 0.5 to 9.6 ) prior to the survey. ${ }^{14}$ Using a 54 item validated questionnaire (Gastrointestinal Quality-of-Life Index), the authors found $81 \%$ of the patients were at least somewhat pleased with their bowel frequency, but $41 \%$ cited abdominal pain, $21 \%$ incontinence, and $46 \%$ diarrhea at least some of the time. However, 93\% stated they would undergo subtotal colectomy again if given a second chance.

\section{Complications}

Morbidity after surgery includes several factors. The risks of colonic resection are related to anastomosis (leak, stricture), infections (wound and intraabdominal abscess), bleeding, and the anesthesia required to accomplish the procedure. The mortality related to the colectomy in this group of relatively healthy patients has been less than $1 \%$. Postoperative small bowel obstruction has been the most frequent complication after total abdominal colectomy. The reported incidence ranges from 8 to $44 \%$ with surgical intervention required in 41 to $100 \%{ }^{1,18}$ The etiology for obstruction has been adhesions resulting from the extensive colectomy and a proposed neuropathic disorder of the myenteric plexus affecting bowel motility. ${ }^{1,19}$ The increasing use of antiadhesive agents such as Seprafilm ${ }^{\circledR}$ (Genzyme Corp., Cambridge, $\mathrm{MA}$ ) and laparoscopic techniques may reduce the incidence of this complication.

Postoperative functional results remain a major issue. Recurrent or persistent constipation has been reported in 0 to $33 \%$ of patients. ${ }^{14} \mathrm{~A}$ review of published reports for the last two decades identified a mean of $41 \%$ of patients had persistent abdominal pain. ${ }^{14}$ Bloating and symptoms related to irritable bowel remain common.

Diarrhea following colectomy is usually a short-term problem. However, in a few patients, the failure of intestinal adaptation can result in intractable diarrhea. The reported incidence of diarrhea has varied from 0 to $46 \%{ }^{14}$ During the adaptation phase, adjuvant measures such as fiber, motility agents (loperamide, diphenoxylate and atropine sulfate, or codeine), and binders (cholestyramine) may assist in reducing bowel frequency. Diarrhea that fails to resolve may necessitate conversion to an ileostomy or consideration of a revision to a pouch-rectal anastomosis. Postoperative incontinence has been reported in 0 to $52 \%$ of patients with a mean of $14 \%$. The reported incidence of conversion 
to a permanent ileostomy has ranged from 0 to $28 \%$ with a mean of $5 \%{ }^{14}$

\section{Summary}

For properly selected patients with colonic inertia and normal rectal function, total abdominal colectomy and ileorectal anastomosis with an open or laparoscopic technique can provide good results. However, patients and surgeons must be aware of the risks and potential outcomes.

\section{References}

1 Beck DE. Colectomy for colonic inertia. Semin Colon Rectal Surg 1992;3:115-119

2 Beck DE, Jagelman DG, Fazio VW. The surgery of idiopathic constipation. Gastroenterol Clin North Am 1987;16(1):143-156

3 Beck DE. Initial evaluation. In: Wexner SD, Bartolo DCC, eds. Constipation: Etiology, Evaluation, and Management. London: Butterworth-Heinemann; 1994:31-38

4 Beck DE. Simplified balloon expulsion test. Dis Colon Rectum 1992;35(6):597-598

5 Pikarsky AJ, Singh JJ, Weiss EG, Nogueras JJ, Wexner SD. Long-term follow-up of patients undergoing colectomy for colonic inertia. Dis Colon Rectum 2001;44(2):179-183

6 Pemberton JH, Rath DM, Ilstrup DM. Evaluation and surgical treatment of severe chronic constipation. Ann Surg 1991;214 (4):403-411, discussion 411-413

7 Todd IP. Constipation: results of surgical treatment. Br J Surg 1985;72(Suppl):S12-S13

8 Beck DE, Fazio VW, Jagelman DG, Lavery IC. Surgical management of colonic inertia. South Med J 1989;82(3):305-309

9 Zenilman ME, Dunnegan DL, Soper NJ, Becker JM. Successful surgical treatment of idiopathic colonic dysmotility. The role of preoperative evaluation of coloanal motor function. Arch Surg 1989;124(8):947-951

10 Wexner SD, Daniel N, Jagelman DG. Colectomy for constipation: physiologic investigation is the key to success. Dis Colon Rectum 1991;34(10):851-856

11 Mahendrarajah K, Van der Schaaf AA, Lovegrove FT, Mendelson R, Levitt MD. Surgery for severe constipation: the use of radioisotope transit scan and barium evacuation proctography in patient selection. Aust N Z J Surg 1994;64(3):183-186

12 Piccirillo MF, Reissman P, Wexner SD. Colectomy as treatment for constipation in selected patients. Br J Surg 1995;82(7): 898-901

13 Redmond JM, Smith GW, Barofsky I, Ratych RE, Goldsborough DC, Schuster MM. Physiological tests to predict long-term outcome of total abdominal colectomy for intractable constipation. Am J Gastroenterol 1995;90(5):748-753

14 FitzHarris GP, Garcia-Aguilar J, Parker SC, et al. Quality of life after subtotal colectomy for slow-transit constipation. Dis Colon Rectum 2003;46:433-440
15 Beck DE. Colectomy for colonic inertia. Clin Colon Rectal Surg 2005;18:81-84

16 Nyam DC, Pemberton JH, Ilstrup DM, Rath DM. Long-term results of surgery for chronic constipation. Dis Colon Rectum 1997;40 (3):273-279

$17 \mathrm{Lim}$ JF, Ho YH. Total colectomy with ileorectal anastomosis leads to appreciable loss in quality of life irrespective of primary diagnosis. Tech Coloproctol 2001;5(2):79-83

18 Vasilevsky CA, Nemer FD, Balcos EG, Christenson CE, Goldberg SM. Is subtotal colectomy a viable option in the management of chronic constipation? Dis Colon Rectum 1988;31(9):679-681

19 Krishnamurthy S, Schuffler MD, Rohrmann CA, Pope CE II. Severe idiopathic constipation is associated with a distinctive abnormality of the colonic myenteric plexus. Gastroenterology 1985;88(1 Pt 1):26-34

20 Glia A, Akerlund JE, Lindberg G. Outcome of colectomy for slowtransit constipation in relation to presence of small-bowel dysmotility. Dis Colon Rectum 2004;47(1):96-102

21 Thaler K, Dinnewitzer A, Oberwalder M, et al. Quality of life after colectomy for colonic inertia. Tech Coloproctol 2005;9(2):133137

22 Hassan I, Pemberton JH, Young-Fadok TM, et al. Ileorectal anastomosis for slow transit constipation: long-term functional and quality of life results. J Gastrointest Surg 2006;10(10):13301336, discussion 1336-1337

23 Choe EK, Park SH, Park KJ. Colonic pseudo-obstruction with distinct transition zone in adult constipation patients: pathological analysis and results of surgical treatment. Am Surg 2011;77 (6):736-742

24 Zutshi M, Hull TL, Trzcinski R, Arvelakis A, Xu M. Surgery for slow transit constipation: are we helping patients? Int J Colorectal Dis 2007;22(3):265-269

25 Hsiao KCW, Jao SW, Wu CC, Lee TY, Lai HJ, Kang JC. Hand-assisted laparoscopic total colectomy for slow transit constipation. Int J Colorectal Dis 2008;23(4):419-424

26 Jiang CQ, Qian Q, Liu ZS, Bangoura G, Zheng KY, Wu YH. Subtotal colectomy with antiperistaltic cecoproctostomy for selected patients with slow transit constipation-from Chinese report. Int J Colorectal Dis 2008;23(12):1251-1256

27 O'Brien S, Hyman N, Osler T, Rabinowitz T. Sexual abuse: a strong predictor of outcomes after colectomy for slow-transit constipation. Dis Colon Rectum 2009;52(11):1844-1847

28 Pinedo G, Zarate AJ, Garcia E, Molina ME, Lopez F, Zúñiga A. Laparoscopic total colectomy for colonic inertia: surgical and functional results. Surg Endosc 2009;23(1):62-65

29 Riss S, Herbst F, Birsan T, Stift A. Postoperative course and long term follow up after colectomy for slow transit constipation-is surgery an appropriate approach? Colorectal Dis 2009;11(3):302307

30 Di Fabio F. Poor quality of life in patients undergoing total colectomy and ileorectal anastomosis for intractable slow-transit constipation. Dis Colon Rectum 2010;53(6):959-960

31 Sohn G, Yu CS, Kim CW, et al. Surgical outcomes after total colectomy with ileorectal anastomosis in patients with medically intractable slow transit constipation. J Korean Soc Coloproctol 2011;27(4):180-187 